\title{
REABILITAÇÃO FUNCIONAL DE UM CANINO COM LESÃO TRAUMÁTICA BILATERAL NAS ARTICULAÇÕES CÁRPICAS - RELATO DE CASO
}

(Functional rehabilitation of a canine with bilateral traumatic injury in carpal joints - Case report)

Eduardo Lux, Marina Soethe, Fabiano Zanini Salbergo

Universidade do Estado de Santa Catarina - Centro de Ciências Agroveterinárias, Brasil

*Correspondência: medvet.elux@gmail.com

Resumo: O presente relato visou a utilização da fisioterapia com o propósito de reduzir a contratura articular e dos tendões flexores cárpicos, reeducar a contratura muscular e favorecer o realinhamento postural em um quadro de lesão traumática. Foi atendido no setor de fisioterapia do hospital veterinário da UDESC, um canino, macho, SRD, com dois meses de idade. O animal não possuía histórico pregresso, pois havia sido resgatado recentemente. No exame físico, observou-se deformidade flexural em ambos os membros torácicos, com locomoção apoiada sobre o carpo dorsalmente, os quais apresentavam calos de apoio. No exame radiográfico, verificou-se subluxação radiocárpica e carpometacárpica esquerda e aumento de volume com radiopacidade em tecidos moles bilateralmente. Com base nos achados, o diagnóstico resultou em lesão traumática bilateral. O protocolo consistiu nas modalidades de laserterapia, ultrassom terapêutico e cinesioterapia, realizando-se 36 sessões com intervalo de 48 horas. A laserterapia (AsGa $904 \mathrm{~nm}$ ) foi utilizada na dosimetria de $5 \mathrm{~J} / \mathrm{cm}^{2}$ com aplicação pontual e equidistante em 8 pontos circundantes à região cárpica bilateralmente. $\mathrm{O}$ ultrassom terapêutico foi empregado em modo contínuo, frequência de $3 \mathrm{MHz}$, intensidade de $0,3 \mathrm{~W} / \mathrm{cm}^{2}$, em movimentos oscilatórios sobre os tendões flexores do carpo durante $3 \mathrm{~min}$. A cinesioterapia constituiu-se de exercícios proprioceptivos de extensão da articulação radiocárpica, sendo executados 10 ciclos em cada membro. Ao final das sessões, uma bandagem ortopédica do tipo Robert-Jones modificada era adaptada da região distal do rádio até a região distal do carpo. Em relação à evolução do paciente, ao final da $3^{a}$ sessão, observou-se o início do apoio dos membros torácicos ao solo com os carpos estendidos, embora o posicionamento ainda não fosse adequado e houvesse uma menor extensão do carpo esquerdo quando comparado ao direito. O posicionamento incorreto do apoio reduziu progressivamente, ao passo que houve diminuição significativa da contratura muscular e articular ao término da $9^{a}$ sessão. A bandagem ortopédica foi utilizada até a $11^{a}$ sessão, quando a amplitude dos movimentos de extensão e flexão cárpicas e a sustentação do peso passaram a ser executados em postura correta. Entre a $12^{\mathrm{a}}$ e $18^{\mathrm{a}}$ sessão, houve progresso no realinhamento postural dos membros e na sustentação adequada do peso. Entre a $19^{a}$ e $36^{a}$ sessão, o animal apresentava postura apropriada tanto em estação quanto em marcha, havendo o acompanhamento em razão do período de crescimento do animal. Considera-se que a laserterapia tenha auxiliado no restabelecimento da postura correta das articulações dos membros torácicos e na resolução dos calos de apoio. Ao ultrassom terapêutico atribuiu-se a resolução da contratura muscular e articular, especialmente por suas propriedades térmicas. À cinesioterapia atribuiu-se o auxílio no ganho de amplitude dos movimentos e na prevenção aos danos articulares gerados pelo desuso, enquanto a bandagem auxiliou na manutenção do posicionamento ortostático da articulação, evitando lesões secundárias (VICENTE; HUMMEL, 2019). Pode-se concluir que as modalidades fisioterapêuticas empregadas se demonstraram eficazes e seguras para o paciente deste relato, uma vez que os objetivos estipulados foram alcançados com êxito e pode-se verificar uma melhora satisfatória no restabelecimento do uso funcional dos membros torácicos do paciente.

Palavras-chave: cinesioterapia; laserterapia; ultrassom terapêutico

Referência: VICENTE, G; HUMMEL, J. Tratado de fisioterapia e fisiatria em pequenos animais. São Paulo: Paya, 2019. 